REVIEW

\title{
Incidence and determinants of lower extremity running injuries in long distance runners: a systematic review
}

\author{
R N van Gent, D Siem, M van Middelkoop, A G van Os, S M A Bierma-Zeinstra, B W Koes
}

Br J Sports Med 2007;41:469-480. doi: 10.1136/bjsm.2006.033548

The purpose of this study was to present a systematic overview of published reports on the incidence and associated potential risk factors of lower extremity running injuries in long distance runners. An electronic database search was conducted using the PubMed-Medline database. Two observers independently assessed the quality of the studies and a best evidence synthesis was used to summarise the results. The incidence of lower extremity running injuries ranged from $19.4 \%$ to $79.3 \%$. The predominant site of these injuries was the knee. There was strong evidence that a long training distance per week in male runners and a history of previous injuries were risk factors for injuries, and that an increase in training distance per week was a protective factor for knee injuries.

See end of article for authors' affiliations

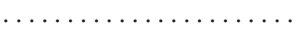

Correspondence to: Marienke van Middelkoop, Erasmus MC Rotterdam, Dr Molewaterplein 50, Rotterdam, Netherlands; m.vanmiddelkoop@ erasmusmc.nl

Accepted 13 March 2007 Published Online First 1 May 2007
$\mathrm{S}$ ports activities and exercises are known to have a positive influence on a person's physical fitness, as well as to reduce the incidence of obesity, cardiovascular disease, and many other chronic health problems. ${ }^{1-4}$ Because of its easy accessibility, long distance running is practised by many people and along with the growing interest in disease prevention it continues to increase in popularity. However, running may also cause injuries, especially to the lower extremities. Various studies have reported on the prevalence and incidence of running injuries occurring in long distance runners during training or races. ${ }^{25}$ Risk factors contributing to these injuries have also been reported. ${ }^{25} 6$

To help prevent such injuries it is necessary to summarise knowledge about potential risk factors. Thus the primary purpose of this study was to present an overview of published reports describing the incidence of various running injuries of the lower extremities in long distance runners. Our second aim was to identify risk factors associated with these running injuries.

\section{METHODS}

\section{Search}

The PubMed-Medline database, available through the NCBI (National Center for Biotechnology Information), was consulted up to January 2006 using search items concerning running injuries combined with the anatomical sites at which these injuries occur, and search items excluding specific publication types in which we were not interested. The search strategy is specified in the appendix. Additionally, all references in the articles included were screened according to the criteria described below.

Relevant review publications and randomised controlled trials in Pubmed were searched from the beginning of the database up to May 2006.

\section{Study criteria}

Abstracts

The search in PubMed-Medline produced a group of abstracts which were screened using the following criteria:

- The subject of the study was running injuries to the lower extremities occurring in long distance runners. We included only studies where subjects ran $\geqslant 5 \mathrm{~km}$ per training or race, or both.

- The runners were recreational or competitive runners, but not belonged to the elite group (which presumably can rely on a better medical support).

- The study described epidemiology (prevalence, incidence) or aetiology (determinants) of lower extremity running injuries, or both.

- The study included a study population of at least 10 individuals (cross sectional studies, prospective cohort studies, retrospective cohort studies, casecontrol studies, case series and clinical trials).

- The study was written in English, Dutch, German, French, Spanish, Italian, Danish, Norwegian, Swedish, Icelandic or Indonesian.

\section{Full text articles}

Based on this first screening a selection of articles was made, which was further narrowed down using the following criteria after reading the full text of the articles:

Inclusion criteria: prospective cohort studies, cross sectional studies, retrospective cohort studies with a follow up period of maximum one month, and randomised clinical trials.

Exclusion criteria: studies in which the participants were predominantly exposed to types of sporting activity other than running (such as triathlon, military training programmes, and so on), and studies describing populations, which only take part in cross country running.

\section{Quality scoring}

To analyse the quality of the selected studies we used the following list of questions: (1) a clear definition of inclusion criteria; (2) description of demographic characteristics; (3) use of a prospective study design; (4) follow up of at least $80 \%$ of the included subjects; (5) information of withdrawals describing their demographic characteristics. 
To examine risk factors appropriately we sought: (6) measurement of determinants at baseline or independently from injuries (blinding); (7) presentation of data and statistical significance (percentages, odds ratios (ORs), relative risks (RRs), p values); (8) the use of multivariate analysis to adjust for other risk factors and confounding variables.

The quality score was calculated for each study, based on the sum of the eight items specified above and scored as positive. It could therefore range from 0 to 8 . Articles were judged as high quality studies when they had a quality score of 4 or more ( $\geqslant 50 \%$ of the maximum attainable score). Two observers (RNvG and DS) obtained the quality scores of the studies independently, so that $\kappa$ values could be calculated to describe the interobserver agreement. The $\kappa$ values both for the interobserver agreement in studies describing the incidence or prevalence of lower extremity running injuries (in this calculation questions 6,7 , and 8 were left out of consideration) and for the interobserver agreement in studies describing determinants for these injuries (in this calculation all eight questions were included) were calculated separately. A $\kappa$ value of $>0.7$ indicates a high level of agreement between assessors, a value between 0.5 and 0.7 a moderate level of agreement, and a value $<0.5$ a poor level of agreement. ${ }^{7}$ In case of disagreement, a final decision was made by a third observer (SMAB-Z).

\section{Analysis}

SPSS 10.1 was used to calculate $\kappa$ values of the quality score. For the determinants of injuries, we calculated some ORs that were not given in the reports but could be obtained from the raw data. To summarise ORs and RRs, a best evidence synthesis was used, because clinical and statistical homogeneity across the studies was absent. The level of evidence was ranked based on the guidelines of Van Tulder $e t l^{8}$ and was divided in the following levels:

- Strong evidence: consistent findings (in $\geqslant 75 \%$ of the studies) among multiple $(\geqslant 2)$ high quality studies.

- Moderate evidence: consistent findings (in $\geqslant 75 \%$ of the studies) among one high quality study and multiple low quality studies.

- Limited evidence: consistent findings (in $\geqslant 75 \%$ of the studies) among multiple low quality studies or one high quality study.

- Conflicting evidence: provided by conflicting findings (fewer than $75 \%$ of the studies reported consistent findings).

Only statistically significant associations were considered as associated factors.

\section{RESULTS}

After examining the 1113 titles and abstracts, 172 articles were identified as potentially relevant. The full texts of 166 of these articles were retrieved (this was not possible for six), and were subsequently evaluated by both observers. Review of the complete texts excluded 155 articles, because they did not meet our criteria; thus 11 articles were selected in our study. In addition to this selection, we included six more articles after searching through the references of these 11 selected articles. Therefore our final selection comprised 17 articles (1.5\%). Most of these were published in English, but there were two foreign language publications (one German and one Norwegian).

\section{Description of the studies}

Thirteen prospective cohort studies ${ }^{9-21}$ and four retrospective cohort studies ${ }^{22-25}$ were included. The study characteristics of the selected studies were described to obtain insight into the homogeneity of the study populations (table 1).
The follow up period in the studies ranged from 1 day to 18 months. The studies contained runners participating in specific training programmes or races from $4 \mathrm{~km}$ to a full marathon. Two studies included runners who were followed during one season of training and race participation. ${ }^{913}$ In one of the studies, runners wished to be notified of upcoming road races, but their exact training programme or race attendance was unknown. ${ }^{14}$ The proportions of subjects analysed ranged from $41.8 \%$ to $100 \%$. Both the population characteristics and the injury definition differed between the various reports. The quality score of the studies ranged from 2 to 7 (table 2).

Four studies were judged as of low quality. ${ }^{11} 182224$ The interobserver agreement in studies describing the incidence or prevalence, or both, of lower extremity running injuries was moderate, with a $\kappa$ value of 0.60 (agreement in $83 \%$ of the questions), whereas in studies describing determinants for these injuries the $\kappa$ value of 0.58 showed a moderate level of agreement (agreement in $82 \%$ of the questions). Disagreements were especially seen in items 2,4 , and 5 , whereas in only two studies were more than two disagreements found..$^{1021}$

\section{Incidence of injuries}

The overall incidence of lower extremity injuries found in the 17 studies varied from $19.4 \%$ to $79.3 \% .^{9}{ }^{12} 141921-24$ In other studies in which non-lower-extremity injuries were also described and included in the overall incidence number, the reported incidence for injuries varied from $26.0 \%$ to $92.4 \% .^{10111317182025}$ The predominant site of lower extremity injuries was the knee, for which the location specific incidence ranged from $7.2 \%$ to $50.0 \%$. Injuries of the lower leg (shin, Achilles tendon, calf, and heel), foot (also toes), and upper leg (hamstring, thigh, and quadriceps) were common, ranging from $9.0 \%$ to $32.2 \%, 5.7 \%$ to $39.3 \%$, and $3.4 \%$ to $38.1 \%$, respectively. Less common sites of lower extremity injuries were the ankle and the hip/pelvis (also groin), ranging from 3.9\% to $16.6 \%$ and $3.3 \%$ to $11.5 \%$, respectively (table 3). ${ }^{910} 12-141618-2224$

Only five studies described incidence figures for specific types of injuries (table 4). ${ }^{11} 15162225$

Two studies also reported the incidence numbers of injuries presented at medical aid posts during a race: $6.2 \%^{16}$ and $17.9 \%{ }^{15}$ of runners participating in a marathon and $3.6 \%$ of runners participating in a half marathon. ${ }^{15}$

\section{Determinants of injuries}

We divided the determinants into four categories: systemic factors (table 5), running/training related factors (table 6), health factors (table 7), and lifestyle factors (table 8). Based on the large heterogeneity in the studies, pooling of the results was not possible, leaving us to present a best evidence synthesis.

\section{Systemic factors}

Greater age was reported to be a significant risk factor for incurring running injuries in four high quality studies. ${ }^{15} 171921$ However, in two high quality studies greater age was reported to be a significant protective factor. ${ }^{17}{ }^{25}$ Therefore there is conflicting evidence over whether greater age is a risk factor for overall lower extremity running injuries. There was, however, limited evidence that greater age was positively associated with front thigh injuries but protective against calf injuries. ${ }^{17}$

The only significant association for overall lower extremity running injuries showed a positive relation with female sex..$^{15}$ There was also limited evidence that female runners were more prone to incur hip injuries, and limited evidence that male runners were at greater risk of getting hamstring or calf injuries. ${ }^{17}$

There was limited evidence that a lower leg length difference was associated with overall lower extremity running injuries, and that a higher left tubercle-sulcus angle or a greater knee 


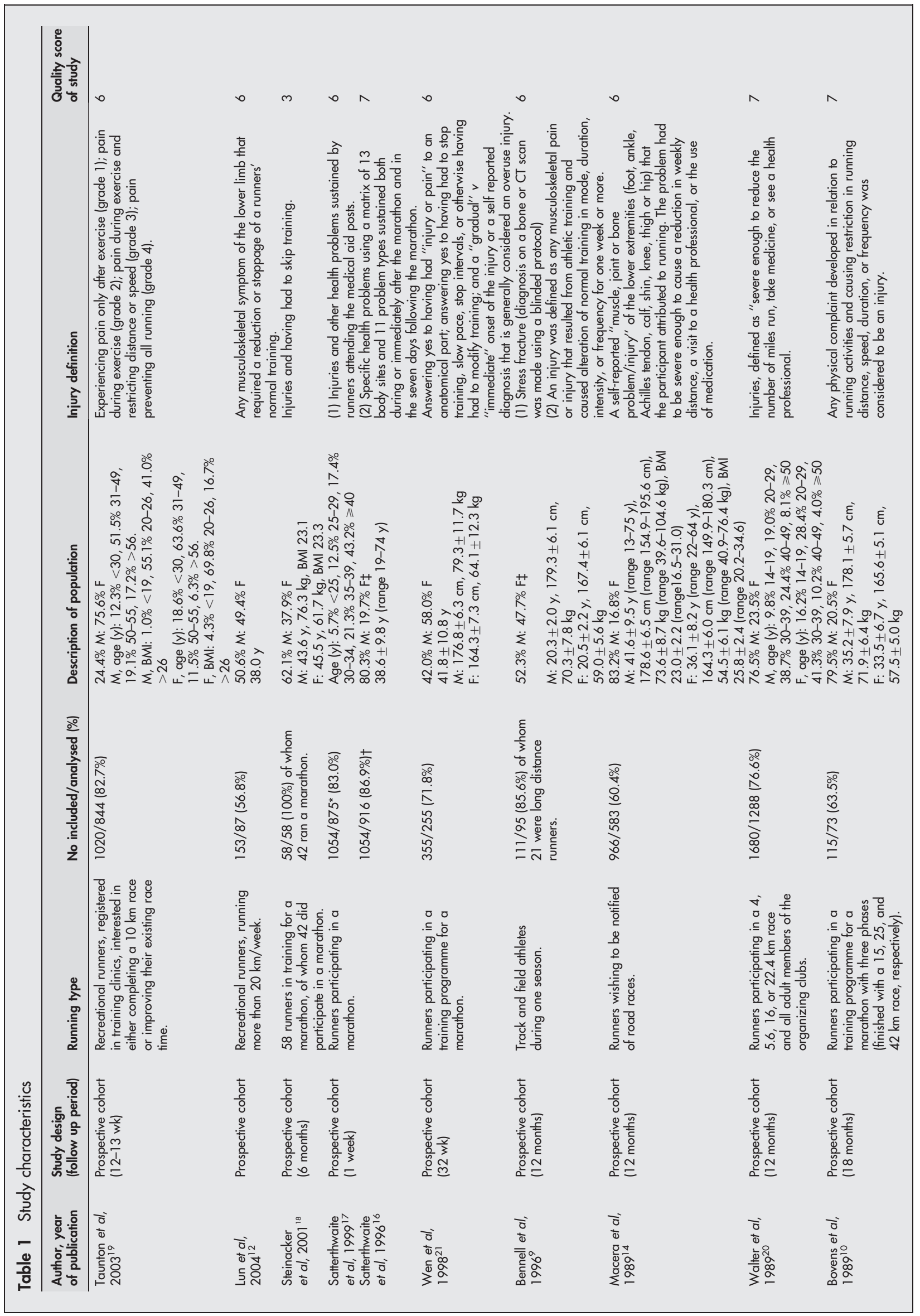




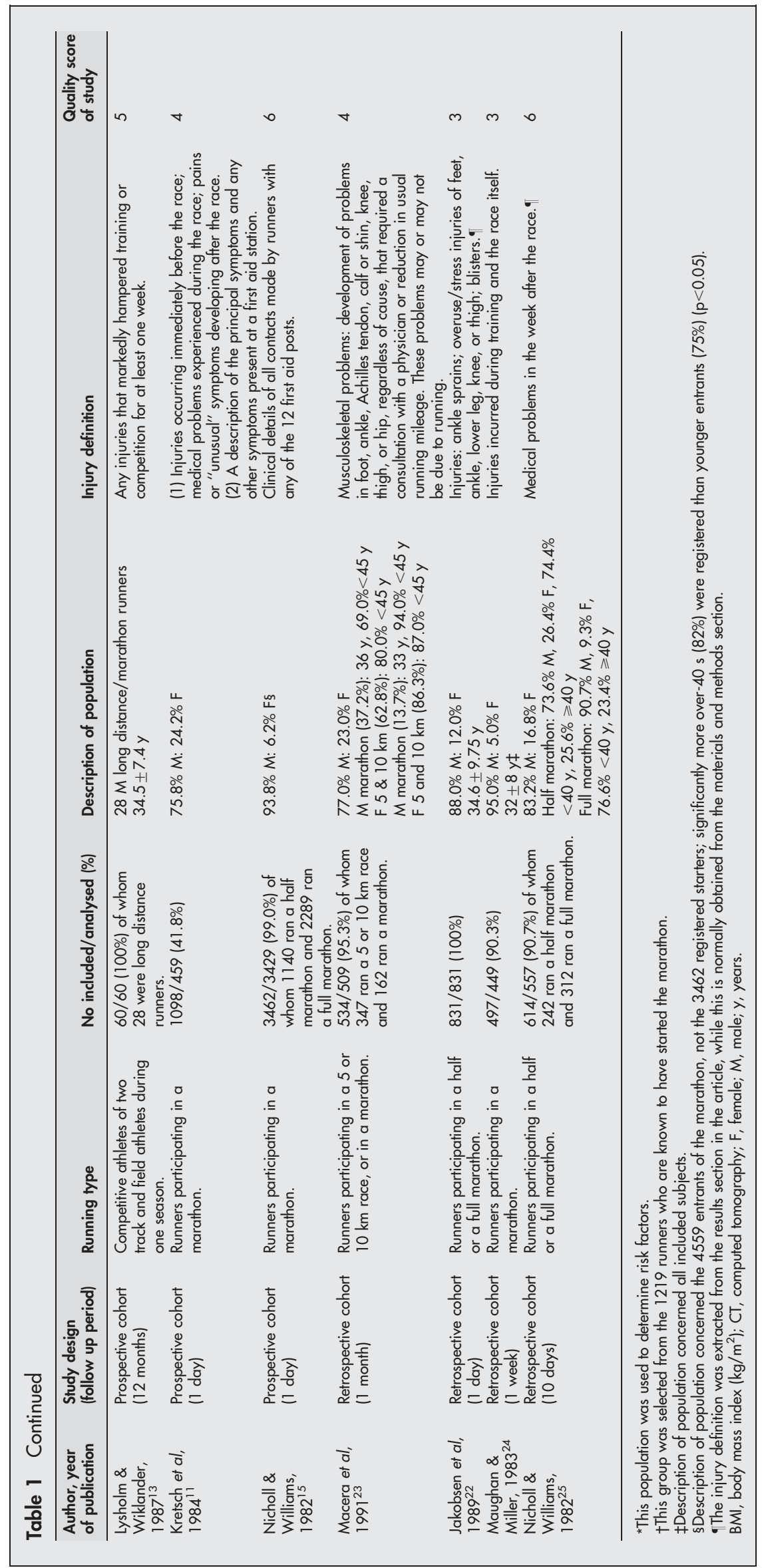


Table 2 Quality scores of the articles selected

\begin{tabular}{|c|c|c|c|c|c|c|c|c|c|}
\hline \multirow[b]{2}{*}{ Articles } & \multicolumn{8}{|l|}{ Questions } & \multirow[b]{2}{*}{ Outcome } \\
\hline & Definition & Demographics & $\begin{array}{l}\text { Prospective } \\
\text { design }\end{array}$ & $\begin{array}{l}80 \% \\
\text { follow up }\end{array}$ & Withdrawals & Blinding & $\begin{array}{l}\text { Data } \\
\text { presentation }\end{array}$ & $\begin{array}{l}\text { Multivariate } \\
\text { analysis }\end{array}$ & \\
\hline Taunton et al, $2003^{19}$ & + & + & + & + & - & - & + & + & 6 \\
\hline Lun et al, $2004^{12}$ & + & + & + & - & + & + & + & - & 6 \\
\hline Satterthwaite et al, $1999^{17}$ & + & + & + & + & - & - & + & + & 6 \\
\hline Wen et al, $1998^{21}$ & + & + & + & - & + & + & + & + & 7 \\
\hline Bennell et al, $1996^{\circ}$ & + & + & + & + & - & + & + & - & 6 \\
\hline Macera et al, $1991^{23}$ & + & + & - & + & - & - & + & + & 5 \\
\hline Macera et al, $1989^{14}$ & + & + & + & - & + & - & + & + & 6 \\
\hline Walter et al, $1989^{20}$ & + & + & + & - & + & + & + & - & 6 \\
\hline Jakobsen et al, $1989^{22}$ & + & + & - & - & - & - & + & - & 3 \\
\hline Kretsch et al, $1984^{11}$ & + & - & + & - & - & - & + & - & 3 \\
\hline Nicholl \& Williams, $1982^{15}$ & + & + & + & + & - & + & + & - & 6 \\
\hline Nicholl \& Williams, $1982^{25}$ & + & + & - & + & - & + & + & - & 5 \\
\hline Steinacker et al, $2001^{18}$ & - & + & + & - & - & na & na & na & 2 \\
\hline Satterthwaite et al, $1996^{16}$ & + & + & + & + & - & $\mathrm{na}$ & na & na & 4 \\
\hline Bovens et al, $1989^{10}$ & + & + & + & - & + & na & na & na & 4 \\
\hline Lysholm \& Wiklander, $1987^{13}$ & + & + & + & + & - & na & na & na & 4 \\
\hline Maughan \& Miller, $1983^{24}$ & + & + & - & - & - & na & na & na & 2 \\
\hline
\end{tabular}

Questions that could be answered with yes are " + "; those answered with no or unknown are "-_"; " ${ }^{\prime \prime}$ scores 1 and "- ${ }^{\prime \prime}$ scores 0.

na, not applicable.

varus were risk factors for shin injuries. ${ }^{21}$ Additionally, there was limited evidence that a higher heel valgus was protective against knee and foot injuries, while a lower heel valgus and a higher right arch index were protective factors only for knee injuries. ${ }^{21}$ There was limited evidence that static biomechanical lower limb alignment was not related to lower limb injuries. ${ }^{12}$

Male runners whose height was 1.70 metres or more were reported to be at a significantly greater risk of suffering new injuries. ${ }^{20}$ Thus there was limited evidence for the positive association between male runners of greater height and lower extremity running injuries.

There was limited evidence that greater weight was protective against foot injuries, ${ }^{21}$ and there was also limited evidence that a body mass index of $>26 \mathrm{~kg} / \mathrm{m}^{2}$ protected male runners from overall lower extremity running injuries. ${ }^{19}$

\section{Running/training related factors}

Only one high quality study reported that male runners were at statistically significant greater risk when running more than two days a week, ${ }^{20}$ whereas conflicting evidence was found for female runners for this association. ${ }^{19}{ }^{20}$ Running a whole year through without a break from training was reported to be a significant risk factor for incurring a lower extremity running injury. As there was only one study that reported this association, there was limited evidence for the association. ${ }^{20}$ There was conflicting evidence for an association between an increase of training and overall lower extremity running injuries. ${ }^{1721}$ An increase of training distance per week was reported as a significant protective factor against knee injuries in two high quality studies, which means there is strong evidence for this association. ${ }^{17} 21$ There was limited evidence that an increase in days of training per week was a risk factor for incurring front thigh injuries, ${ }^{17}$ that an increase of training distance per week was a risk factor for hamstring injuries, ${ }^{17}$ and that an increase of hours training per week was a protective factor for knee as well as foot injuries. ${ }^{21}$

Two high quality studies reported training for more than $64 \mathrm{~km} /$ week as a significant risk factor for male runners incurring lower extremity running injuries, ${ }^{14} 20$ while in female runners this association was only reported in one high quality study. ${ }^{20}$ Thus there was stronger evidence for an association between higher training distance for male runners than for female runners. There was no evidence for an association between training less than $60 \mathrm{~km}$ in the last three months before a marathon and overall lower extremity running injuries, because this association was only significant in one low quality study. ${ }^{11}$

Lower extremity injuries in one high quality study were associated with longer race distances (marathon races compared with 5 and $10 \mathrm{~km}$ races). ${ }^{23}$ Thus there was limited evidence that participating in races of greater distance was a risk factor for incurring these injuries.

There was conflicting evidence for an association between inexperience in running and overall lower extremity injuries. ${ }^{14} 15172125$ An association between hamstring or knee injuries and participation in a marathon for the first time was reported in one high quality study, ${ }^{17}$ while foot injuries were associated with more experienced runners in another high quality study.[32] Thus there was limited evidence for inexperience as a risk factor for hamstring or knee injuries or as a risk factor for foot injuries.

Two high quality studies reported no significant associations between the use of a warm up and lower extremity injuries, implying that there is no such association. ${ }^{14} 20$

There was limited evidence for an association between female runners running on concrete surfaces and lower extremity injuries. ${ }^{14}$ There was no significant association between male runners running on a specific surface and lower extremity injuries and between training on hilly terrain, or running in the dark or in the morning and these injuries, implying that there is no association between these determinants and lower extremity running injuries. ${ }^{14}$

For an association between competitive running and lower extremity running injuries there was limited evidence for male runners only. ${ }^{20}$

There was limited evidence for an association between shin injuries and the use of a greater number of shoes for running. ${ }^{21}$ There was limited evidence that a shoe age of four to six months was a protective factor for lower extremity running injuries in male runners, but was a risk factor in female runners. ${ }^{19}$

No significant association between pace and lower extremity running injuries was reported, implying that there is no association. $^{2122}$

\section{Health factors}

A history of previous injuries was reported to be a significant risk factor for injuries in multiple high quality studies. ${ }^{14202123}$ 


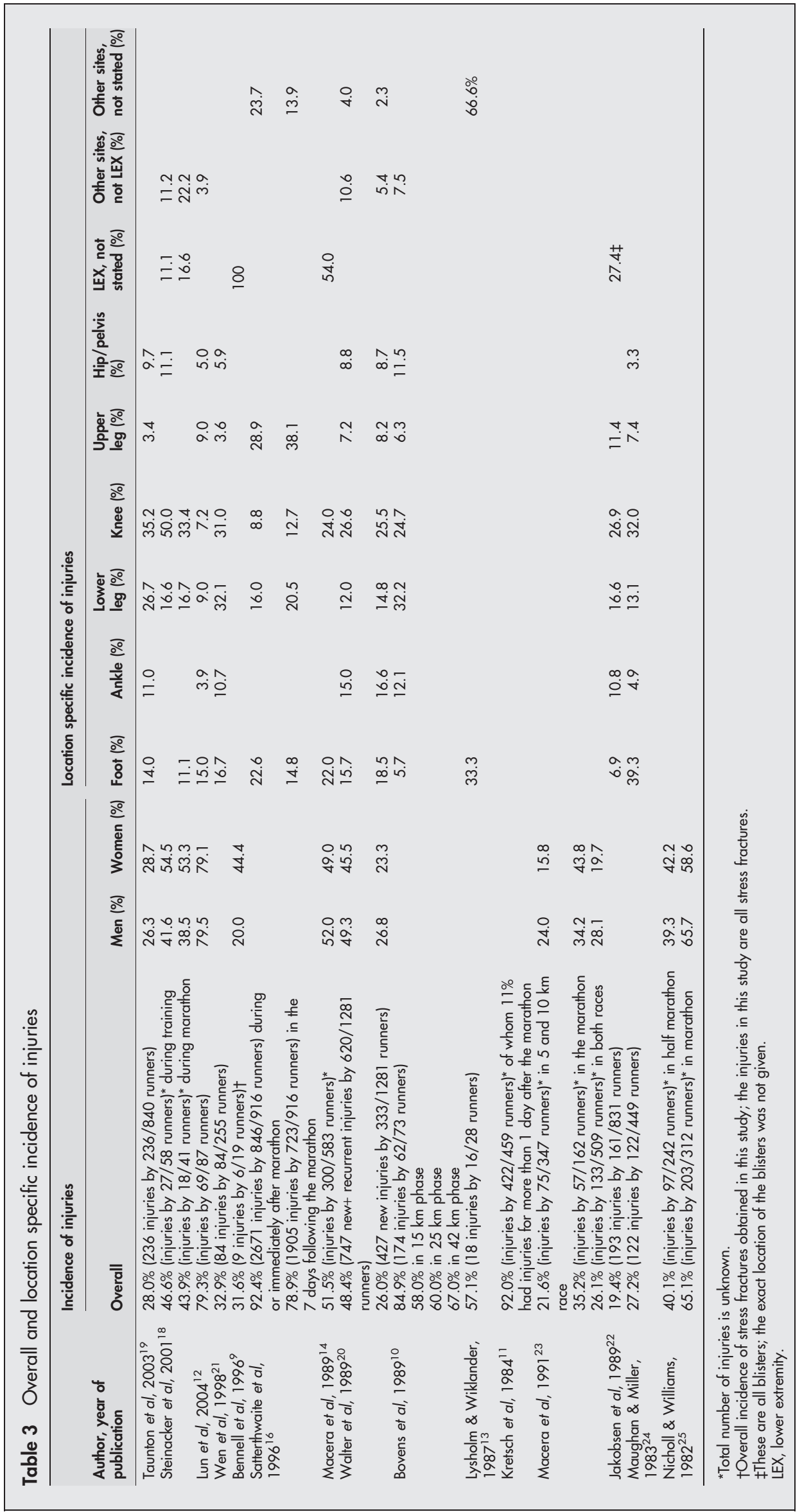

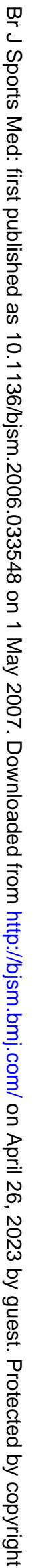




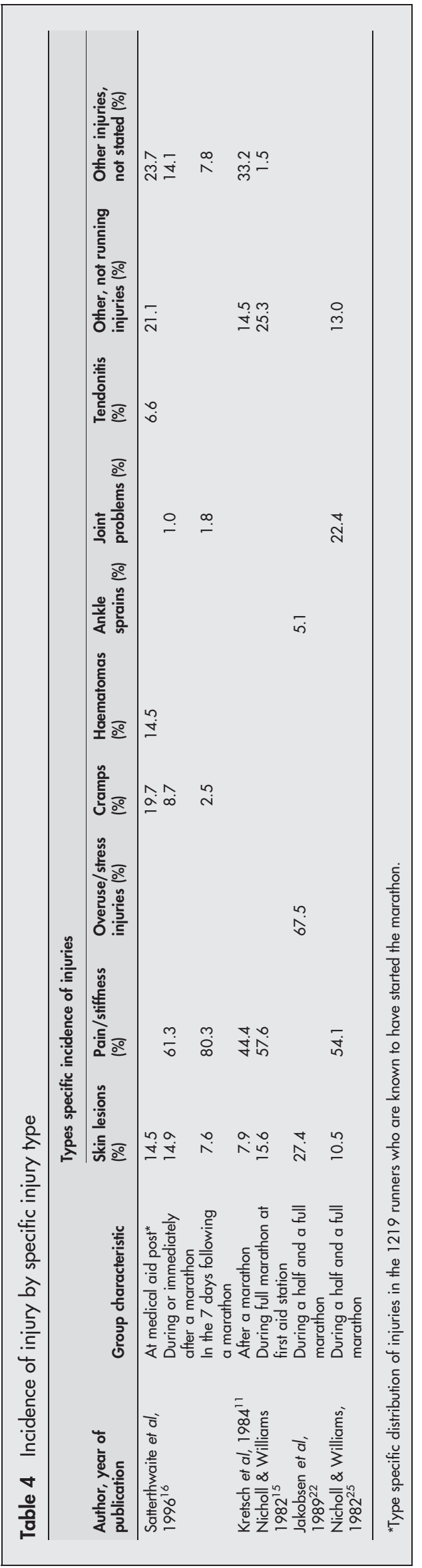

Thus there was strong evidence for an association between a history of previous injuries and lower extremity running injuries. For an association between a positive medical history and these injuries there was only limited evidence. ${ }^{17}$

\section{Lifestyle factors}

There was limited evidence that drinking alcohol was a risk factor for incurring blisters or front thigh injuries and that participation in cycling and aerobics were risk factors for, respectively, front thigh and hamstring injuries. ${ }^{17}$ There was, however, some evidence that smoking was a protective factor against blisters. ${ }^{17}$

\section{DISCUSSION}

Three reviews on running injuries were published more than a decade ago. ${ }^{25-27}$ New studies on running injuries since those reviews have been incorporated into this systematic review. Further, in contrast to the methods used in those reviews, we undertook a systematic search strategy. We also evaluated the quality of the studies included and carried out a best evidence synthesis for determinants of lower extremity running injuries. Thus our review is a rigorous update of earlier reviews and provides evidence of risk factors for these injuries.

\section{Incidence of injuries}

The reported overall incidence of lower extremity running injuries showed a large range (19.4\% to $79.3 \%)$. An increase in the incidence range is mainly seen in studies that also included non-lower-extremity injuries in their incidence numbers ( $19.4 \%$ to $92.4 \%$ ), although higher incidences may partly reflect higher rate of lower extremity injury. Previous reviews reported ranges of $24 \%$ to $83 \%,{ }^{26} 33 \%$ to $85 \%,{ }^{27}$ and $24 \%$ to $77 \% .{ }^{28}$

The most common site of lower extremity injuries was the knee $(7.2 \%$ to $50.0 \%)$, followed by the lower leg $(9.0 \%$ to $32.2 \%)$, the foot $(5.7 \%$ to $39.3 \%)$, and the upper leg $(3.4 \%$ to $38.1 \%)$. Less common sites of lower extremity injuries were the ankle $(3.9 \%$ to $16.6 \%)$ and the hip/pelvis (3.3\% to $11.5 \%)$. Our results supports Van Mechelen's conclusion ${ }^{28}$ that most of running injuries are located in the knee.

\section{Determinants of injuries}

Only limited evidence was found for some of the systemic, lifestyle, and health factors as risk factors for running injuries. These included greater age (a clear cut off point for greater age could not be observed), sex, lower leg length difference, greater left tubercle-sulcus angle and greater knee varus, greater height in male runners, drinking alcohol, participation in cycling and aerobics, and a positive medical history. We found strong evidence for a greater training distance per week in male runners and a history of previous injuries as a risk factor for both male and female runners. There was also strong evidence that increased training distance per week was a protective factor, although only for knee injuries. It remains unclear why increasing weekly distance is protective for knee injuries. However, the relation between distance and injury may not be simple and there may be a fine balance between overuse and underconditioning among long distance runners. For several other training/running related factors we only found limited evidence that they were risk factors (greater training frequency in male runners, running the whole year through, greater training distance in female runners, participation in races of greater distance, women running on concrete surfaces, competitive male runners, increase in days of training per week, increase in training distance per week, level of experience in running, use of more shoes for running, and shoe age).

Although limited evidence was found that greater weight and a body mass index of $>26 \mathrm{~kg} / \mathrm{m}^{2}$ were protective factors, this 
Table 5 Systemic factors for lower extremity injuries

\begin{tabular}{|c|c|c|c|c|}
\hline Determinant & Author & Injury & Specification of determinant & Outcome $(95 \% \mathrm{Cl})$ \\
\hline Age & 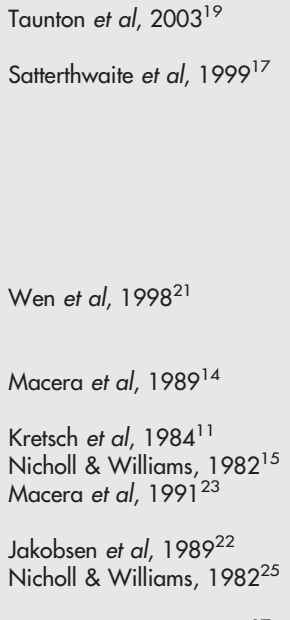 & $\begin{array}{l}\text { Overall injuries* } \\
\text { New injuries* } \\
\text { Stiffness and/or pain in front thigh } \\
\text { Stiffness and/or pain in front thigh } \\
\text { Stiffness and/or pain in front thigh } \\
\text { Stiffness and/or pain in front thigh } \\
\text { Stifffness and/or pain in calf } \\
\text { Stiffness and/or pain in calf } \\
\text { Stifffness and/or pain in calf } \\
\text { Stifffness and/or pain in calf } \\
\text { Knee injuries } \\
\text { Overall injuries* } \\
\text { Lower extremity injuries } \\
\text { Overall injuries* } \\
\text { Overall injuries* } \\
\text { Lower extremity musculoskeletal } \\
\text { problems } \\
\text { Overall injuries } \\
\text { Overall injuries* }\end{array}$ & 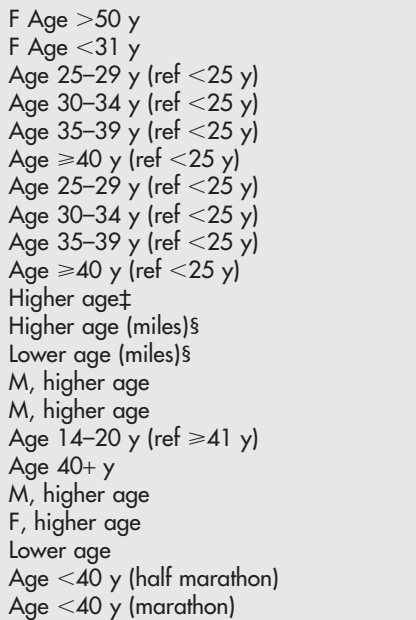 & $\begin{array}{l}R R=1.92(1.11 \text { to } 3.33) \dagger \\
R R=0.58(0.34 \text { to } 0.97) \dagger \\
O R=1.42(0.79 \text { to } 2.53) \dagger \\
O R=1.83(1.04 \text { to } 3.22) \dagger \\
O R=1.34(0.77 \text { to } 2.31) \dagger \\
O R=0.96(0.56 \text { to } 1.63) \dagger \\
O R=0.60(0.32 \text { to } 1.13) \dagger \\
O R=0.43(0.23 \text { to } 0.78) \dagger \\
O R=0.56(0.31 \text { to } 1.01) \dagger \\
O R=0.40(0.23 \text { to } 0.73) \dagger \\
R R=2.09(0.95 \text { to } 4.58) \dagger \\
R R=1.08(0.99 \text { to } 1.17) \dagger \\
R R=0.39(0.15 \text { to } 0.97) \dagger \\
O R=1.0(1.0 \text { to } 1.0) \dagger \\
O R=1.0(0.9 \text { to } 1.0) \dagger \\
p<0.025 \\
p<0.05 \\
O R=1.0(1.0 \text { to } 1.0) \dagger \\
O R=1.0(0.9 \text { to } 1.1) \dagger \\
p<0.01 \\
O R=2.12(1.13 \text { to } 3.98) \\
O R=1.31(0.76 \text { to } 2.25)\end{array}$ \\
\hline Sex & $\begin{array}{l}\text { Bennell et al, } 1996^{9} \\
\text { Macera et al, 1989 } \\
\text { Nicholl \& Williams, } 1982^{15} \\
\text { Macera et al, 1991 } \\
\text { Jakobsen et al, 1989 } 22 \\
\text { Nicholl \& Williams, } 1982^{25}\end{array}$ & $\begin{array}{l}\text { Stiffness and/or pain in hamstring } \\
\text { Stiffness and/or pain in hip } \\
\text { Stiffness and/or pain in calf } \\
\text { Stress fractures } \\
\text { Lower extremity injuries } \\
\text { Overall injuries* } \\
\text { Lower extremity musculoskeletal } \\
\text { problems } \\
\text { Overall injuries } \\
\text { Overall injuries* }\end{array}$ & $\begin{array}{l}M \\
F \\
M \\
F \\
F \\
F \\
F \text { (marathon) } \\
F \text { (5 and } 10 \mathrm{~km}) \\
F \\
F \text { (half marathon) } \\
F \text { (marathon) }\end{array}$ & $\begin{array}{l}O R=1.60(1.04 \text { to } 2.47) \dagger \\
O R=1.88(1.15 \text { to } 3.06) \dagger \\
O R=1.86(1.29 \text { to } 2.68) \dagger \\
O R=3.20(0.42 \text { to } 24.42) \\
O R=0.89(0.58 \text { to } 1.37) \\
p<0.05 \\
O R=1.49(0.53 \text { to } 4.25) \\
O R=0.60(0.32 \text { to } 1.10) \\
p>0.05 \\
O R=1.13(0.63 \text { to } 2.01) \\
O R=0.74(0.34 \text { to } 1.61)\end{array}$ \\
\hline Height & Walter et al, $1989^{20}$ & New injuries* & $\begin{array}{l}M 170-179 \mathrm{~cm} \text { (average) }(\text { ref }<170) \\
M \geqslant 180 \mathrm{~cm} \text { (tallest) (ref }<170) \\
F 160-169 \mathrm{~cm} \text { (average) }(\text { ref }<160) \\
F \geqslant 170 \mathrm{~cm} \text { (tallest) (ref }<160 \text { ) }\end{array}$ & $\begin{array}{l}O R=2.04(1.15 \text { to } 3.46) \dagger \\
O R=2.30(1.29 \text { to } 3.90) \dagger \\
O R=1.29(0.65 \text { to } 2.48) \dagger \\
O R=0.78(0.32 \text { to } 1.97) \dagger\end{array}$ \\
\hline $\begin{array}{l}\text { Weight } \\
\text { BMI }\end{array}$ & $\begin{array}{l}\text { Wen et al, } 1998^{21} \\
\text { Taunton et al, } 2003^{19} \\
\text { Macera et al, } 1989^{14}\end{array}$ & $\begin{array}{l}\text { Foot injuries } \\
\text { Overall injury* } \\
\text { Lower extremity injuries }\end{array}$ & $\begin{array}{l}\text { Higher weightł } \\
\text { M, BMI }>26 \\
\text { M, BMI ( }>74 \text { th centile) } \\
\text { M, BMI ( }<26 \text { th centile) } \\
\text { F, BMI ( }>74 \text { th centile) } \\
\text { F, BMI ( }<26 \text { th centile) }\end{array}$ & $\begin{array}{l}\mathrm{RR}=0.94(0.89 \text { to } 0.99) \dagger \\
\mathrm{RR}=0.41(0.21 \text { to } 0.79) \dagger \\
\mathrm{OR}=0.7(0.5 \text { to } 1.2) \dagger \\
\mathrm{OR}=1.2(0.7 \text { to } 1.9) \dagger \\
\mathrm{OR}=3.0(0.5 \text { to } 18.8) \dagger \\
\mathrm{OR}=2.0(0.6 \text { to } 6.6) \dagger\end{array}$ \\
\hline Alignment & $\begin{array}{l}\text { Lun et al, } 2004^{12} \\
\text { Wen et al, } 1998^{21}\end{array}$ & $\begin{array}{l}\text { Overall injuries } \\
\text { Overall injuries* } \\
\text { Knee injuries } \\
\text { Shin injuries } \\
\text { Foot injuries }\end{array}$ & 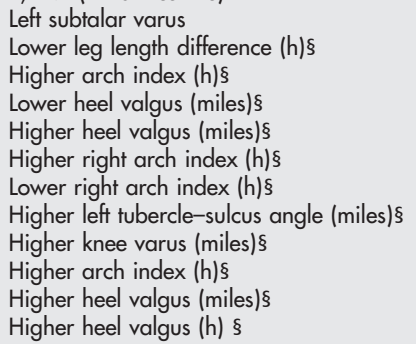 & $\begin{array}{l}\mathrm{Cl}=0.2 \text { to } 4.2 \\
\mathrm{RR}=1.96(1.07 \text { to } 3.58) \dagger \\
\mathrm{RR}=0(0 \text { to } 0.37) \dagger \\
\mathrm{RR}=0.08(0.01 \text { to } 0.74) \dagger \\
\mathrm{RR}=0.09(0.01 \text { to } 0.81) \dagger \\
\mathrm{RR}=0.11(0.01 \text { to } 0.90) \dagger \\
\mathrm{RR}=0.25(0.05 \text { to } 1.20) \dagger \\
\mathrm{RR}=11.02(2.00 \text { to } 60.86) \dagger \\
\mathrm{RR}=1.09(1.03 \text { to } 1.15) \dagger \\
\mathrm{RR}=0(0 \text { to } 8.21) \dagger \\
\mathrm{RR}=0.76(0.58 \text { to } 0.98) \dagger \\
\mathrm{RR}=0.74(0.58 \text { to } 0.94) \dagger\end{array}$ \\
\hline
\end{tabular}

*Not-running injuries and running injuries not involving the lower extremity were included, to establish the outcome.

†Represents adjusted OR or RR.

†RRs were calculated dividing the number of injured runners by the total number of runner-weeks accumulated (relative incidence ratios).

§RRs were obtained from special subgroups in which information on distances run (miles) and time spent running (hours) was measured.

$\mathrm{BMI}$, body mass index; $\mathrm{Cl}$, confidence interval; $\mathrm{F}$, female; $\mathrm{M}$, male; $\mathrm{OR}$, odds ratio; ref, reference; RR, relative risk; $y$, years.

association may be caused by the fact that in these groups of runners less training activity is being undertaken.

\section{Limitations}

Because of the specific search definition and because the language restriction we used to identify studies in the PubMedMedline database, we may have found fewer studies on running related injuries than are available. In the studies identified there was a lack of standard definition of injury. In some studies running injuries were defined as running related injuries to the lower extremities, but other studies also included non-lower-extremity injuries and even problems such as headache, dehydration, fatigue, and others. Further, different study designs, differing data collection methods, and differing methods of determining the denominator might have affected the incidence rates of the studies. Also, the type of runners selected for each study varied-usually a specific selection of runners was made (for example, male runners, recreational runners, runners in training programmes, race participants). All these factors may have influenced the final incidence rates of injuries and the odds ratios and relative risks for the determinants.

We decided only to include studies that investigated long distance runners. The studies of Bennell et $a l^{9}$ and Lysholm and Wiklander ${ }^{13}$ both described a group of track and field athletes; however, they also described a separate group of long distance/ 
Table 6 Running/training related factors for lower extremity injury

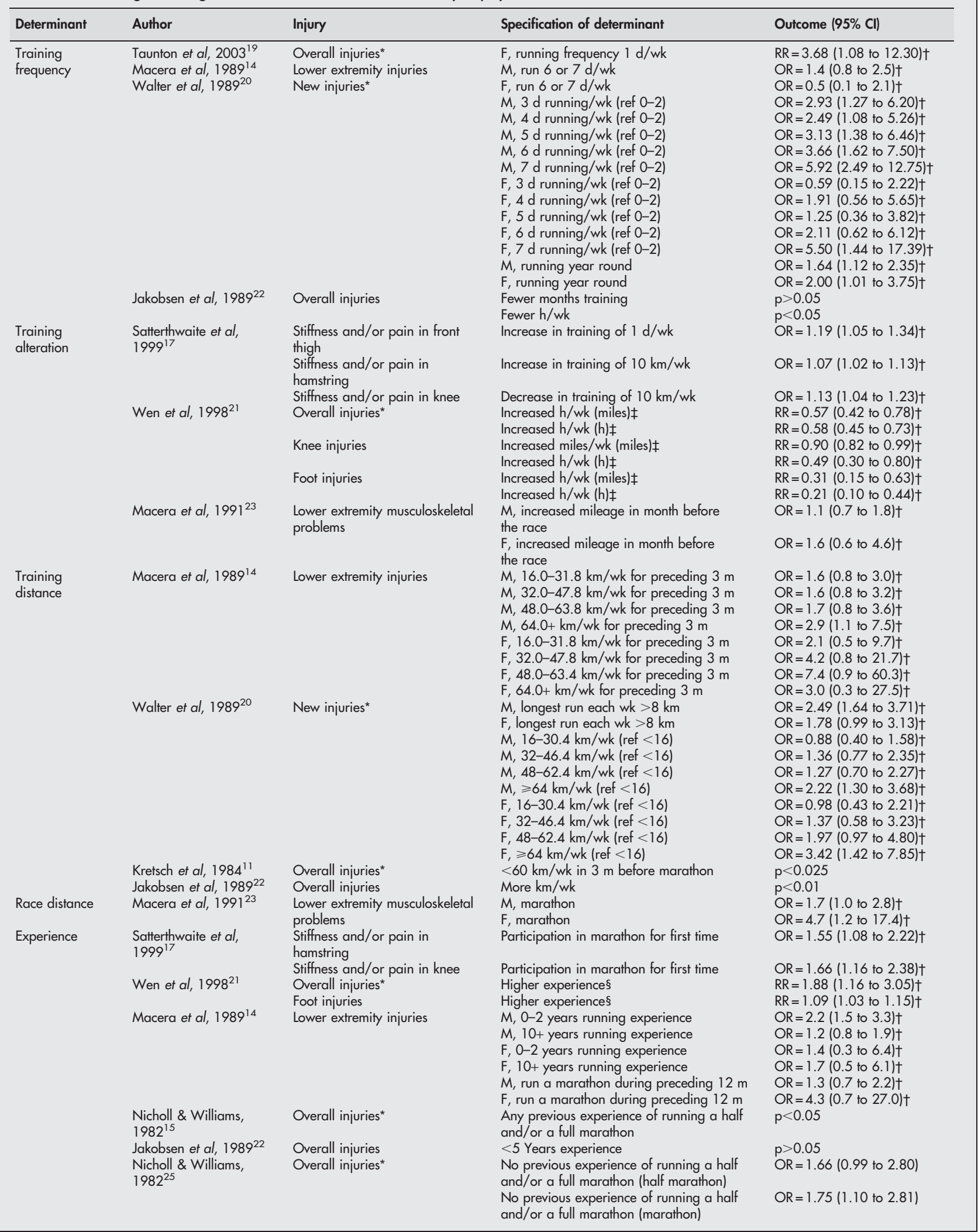


Table 6 Continued

\begin{tabular}{|c|c|c|c|c|}
\hline Determinant & Author & Injury & Specification of determinant & Outcome $(95 \% \mathrm{Cl})$ \\
\hline \multirow[t]{13}{*}{ Warm up } & Macera et al, $1989^{14}$ & Lower extremity injuries & $\begin{array}{l}M \text {, stretch before running } \\
F \text {, stretch before running }\end{array}$ & $\begin{array}{l}O R=1.1(0.8 \text { to } 5.9) \\
O R=1.6(0.7 \text { to } 3.5)\end{array}$ \\
\hline & Walter et al, $1989^{20}$ & New injuries* & $M$, usually using stretching (ref always) & $O R=0.80(0.55$ to 1.17$) \dagger$ \\
\hline & & & $M$, sometimes using stretching (ref always) & $\mathrm{OR}=1.56(1.10$ to 2.21$) \dagger$ \\
\hline & & & $M$, never using stretching (ref always) & $\mathrm{OR}=0.87(0.50$ to 1.57$) \dagger$ \\
\hline & & & $\mathrm{M}$, usually using warm up (ref always) & $\mathrm{OR}=1.03(0.73$ to 1.44$) \dagger$ \\
\hline & & & $M$, sometimes using warm up (ref always) & $\mathrm{OR}=1.30(0.87$ to 1.93$) \dagger$ \\
\hline & & & $M$, never using warm up (ref always) & $\mathrm{OR}=0.37(0.19$ to 0.81$) \dagger$ \\
\hline & & & $\mathrm{F}$, usually using stretching (ref always) & $\mathrm{OR}=0.95(0.48$ to 1.96$) \dagger$ \\
\hline & & & F Sometimes using stretching (ref always) & $\mathrm{OR}=1.78(0.91$ to 3.53$) \dagger$ \\
\hline & & & $F$, never using stretching (ref always) & $\mathrm{OR}=0.85(0.27$ to 3.22$) \dagger$ \\
\hline & & & $\mathrm{F}$, usually using warm up (ref always) & $\mathrm{OR}=0.82(0.42$ to 1.60$) \dagger$ \\
\hline & & & $\mathrm{F}$, sometimes using warm up (ref always) & $\mathrm{OR}=0.95(0.47$ to 1.96$) \dagger$ \\
\hline & & & $\mathrm{F}$, never using warm up (ref always) & $\mathrm{OR}=0.55(0.22$ to 1.51$) \dagger$ \\
\hline \multirow{10}{*}{$\begin{array}{l}\text { Circumstances } \\
\text { of training }\end{array}$} & Macera et al, $1989^{14}$ & Lower extremity injuries & M, hilly terrain & $\mathrm{OR}=1.1(0.7$ to 1.6$)$ \\
\hline & & & $M$, asphalt surface & $\mathrm{OR}=1.2(0.8$ to 1.7$)$ \\
\hline & & & $M$, run in dark & $\mathrm{OR}=0.9(0.6$ to 1.3$)$ \\
\hline & & & $M$, run in morning & $\mathrm{OR}=1.1(0.7$ to 1.7$)$ \\
\hline & & & $\mathrm{F}$, hilly terrain & $\mathrm{OR}=1.0(0.4$ to 2.5$)$ \\
\hline & & & $\mathrm{F}$, asphalt surface & $\mathrm{OR}=1.8(0.8$ to 4.2$)$ \\
\hline & & & $\mathrm{F}$, run in dark & $\mathrm{OR}=1.0(0.4$ to 2.7$)$ \\
\hline & & & $\mathrm{F}$, run in morning & $\mathrm{OR}=1.4(0.6$ to 3.2$)$ \\
\hline & & & $M$, concrete surface & $\mathrm{OR}=1.4(0.8$ to 2.5$) \dagger$ \\
\hline & & & $M$, concrete surface & $\mathrm{OR}=5.6(1.1$ to 29.3$) \dagger$ \\
\hline \multirow[t]{4}{*}{ Type of runner } & Walter et al, $1989^{20}$ & New injuries* & $M$, recreational runner (ref fitness runner) & $\mathrm{OR}=1.18(0.84$ to 1.66$) \dagger$ \\
\hline & & & $M$, competitive runner (ref fitness runner) & $\mathrm{OR}=1.73(1.21$ to 2.49$) \dagger$ \\
\hline & & & $\mathrm{F}$, recreational runner (ref fitness runner) & $\mathrm{OR}=0.71(0.37$ to 1.40$) \dagger$ \\
\hline & & & $\mathrm{F}$, competitive runner (ref fitness runner) & $\mathrm{OR}=1.93(0.97$ to 3.89$) \dagger$ \\
\hline \multirow[t]{4}{*}{ Shoe use } & Taunton et al, $2003^{19}$ & Overall injuries* & $M$, running shoe age $4-6 \mathrm{~m}$ & $\mathrm{RR}=0.36(0.15$ to 0.83$) \dagger$ \\
\hline & & New injuries & $F$, running shoe age $4-6 \mathrm{~m}$ & $\mathrm{RR}=1.74(1.10$ to 2.98$) \dagger$ \\
\hline & & & $F$, running shoe age $1-3 \mathrm{~m}$ & $R R=0.61(0.38$ to 0.99$) \dagger$ \\
\hline & Wen et al, $1998^{21}$ & Shin injuries & Higher number of shoes $(h) \ddagger$ & $\mathrm{RR}=6.91(1.36$ to 35.15$) \dagger$ \\
\hline \multirow[t]{2}{*}{ Pace } & Wen et al, $1998^{21}$ & Shin injuries & More intervals§ & $\mathrm{RR}=14.89(0.50$ to 147.33$) \dagger$ \\
\hline & Jakobsen et al, $1989^{22}$ & Overall injuries & Lower pace & $p=0.06$ \\
\hline
\end{tabular}

*Not-running injuries and running, but not lower extremity, injuries were included to establish the outcome.

tRepresents adjusted OR or RR.

†RRs were obtained from special subgroups in which information on distances run (miles) and time spent running (hours) was measured.

§RRs were calculated dividing the number of injured runners by the total number of runner-weeks accumulated (relative incidence ratios).

$\mathrm{Cl}$, confidence interval; $\mathrm{F}$, female; $\mathrm{m}$, months; $\mathrm{M}$, male; OR, odds ratio; ref, reference; $R R$, relative risk; wk, week.

marathon runners. Both these studies were included in our review because they described the results of the long distance runners separately from the whole track and field athletes group; thus only the results for the long distance runners were included in this study.

The results could also be biased by a self selection process of healthy runners participating in running events or training programmes in the studies included, or by injured runners not responding to questionnaires or overreporting of injuries because of the self reporting nature of some studies.

For some subgroups reported here, there was low power. This might have influenced our conclusions, based on the best evidence synthesis. For example, associations were found for male but not female runners, while the estimate of the

Table 7 Health factors for lower extremity injury

\begin{tabular}{|c|c|c|c|c|}
\hline Determinant & Author & Injury & Specification of determinant & Outcome $(95 \% \mathrm{Cl})$ \\
\hline \multirow[t]{3}{*}{$\begin{array}{l}\text { History of previous } \\
\text { injuries }\end{array}$} & $\begin{array}{l}\text { Wen et al, } 1998^{21} \\
\text { Macera et al, } 1989^{14}\end{array}$ & $\begin{array}{l}\text { Overall injuries* } \\
\text { Shin injuries } \\
\text { Lower extremity injuries }\end{array}$ & $\begin{array}{l}\text { History of previous injuries } t \\
\text { History of old shin injuriest } \\
\mathrm{M} \text {, new lower extremity injury during the } \\
\text { previous } 12 \mathrm{~m} \\
\mathrm{~F} \text {, new lower extremity injury during the } \\
\text { previous } 12 \mathrm{~m}\end{array}$ & $\begin{array}{l}\mathrm{RR}=2.02(1.27 \text { to } 3.21) \ddagger \\
\mathrm{RR}=7.24(2.40 \text { to } 21.82) \ddagger \\
\mathrm{OR}=2.7(2.6 \text { to } 2.7) \ddagger \\
\mathrm{OR}=1.9(0.7 \text { to } 4.9) \ddagger\end{array}$ \\
\hline & $\begin{array}{l}\text { Walter et al, } 1989^{20} \\
\text { Kretsch et al, } 1984^{11}\end{array}$ & $\begin{array}{l}\text { New injuries* } \\
\text { Overall injuries* }\end{array}$ & $\begin{array}{l}M \text {, injured in previous year } \\
F \text {, injured in previous year } \\
\text { Number of medical or physical problems } \\
\text { experienced during training }\end{array}$ & $\begin{array}{l}O R=1.69(1.27 \text { to } 2.25) \ddagger \\
O R=2.35(1.33 \text { to } 4.07) \ddagger \\
p>0.05\end{array}$ \\
\hline & Macera et al, $1991^{23}$ & $\begin{array}{l}\text { Lower extremity } \\
\text { musculoskeletal problems }\end{array}$ & $\begin{array}{l}\text { M, previous musculoskeletal problems in the } \\
\text { past year } \\
\mathrm{F} \text {, previous musculoskeletal problems in the } \\
\text { past year }\end{array}$ & $\begin{array}{l}O R=6.3(3.7 \text { to } 10.8) \ddagger \\
O R=7.6(2.0 \text { to } 28.4) \ddagger\end{array}$ \\
\hline Medical history & $\begin{array}{l}\text { Satterthwaite et al, } \\
1999^{17} \\
\text { Kretsch et al, } 1984^{11}\end{array}$ & $\begin{array}{l}\text { Stiffness and/or pain in } \\
\text { knee } \\
\text { Overall injuries* }\end{array}$ & $\begin{array}{l}\text { Current medication use } \\
\text { Being unwell in last } 2 \text { wk before marathon } \\
\text { Positive medical history }\end{array}$ & $\begin{array}{l}O R=1.56(1.02 \text { to } 2.32) \ddagger \\
O R=1.42(1.03 \text { to } 1.95) \ddagger \\
p<0.025\end{array}$ \\
\hline
\end{tabular}

*Not-running injuries and running, but not lower extremity, injuries were included to establish the outcome.

TRRs were calculated dividing the number of injured runners by the total number of runner-weeks accumulated (relative incidence ratios).

$\ddagger$ Represents adjusted OR or RR.

$\mathrm{Cl}$, confidence interval; $\mathrm{m}$, months; $\mathrm{OR}$, odds ratio; $\mathrm{RR}$, relative risk; wk, week. 
Table 8 Lifestyle factors

\begin{tabular}{|c|c|c|c|c|}
\hline Determinant & Author & Injury & Specification of determinant & Outcome $(95 \% \mathrm{Cl})$ \\
\hline Drinking alcohol & Satterthwaite et al, $1999^{17}$ & $\begin{array}{l}\text { Blisters } \\
\text { Stiffness and/or pain in front thigh }\end{array}$ & $\begin{array}{l}\text { Drinking alcohol } \geqslant 1 / \mathrm{m} \\
\text { Drinking alcohol } \geqslant 1 / \mathrm{m}\end{array}$ & $\begin{array}{l}\mathrm{OR}=1.44(1.01 \text { to } 2.05)^{*} \\
\mathrm{OR}=1.38(1.01 \text { to } 1.88)^{*}\end{array}$ \\
\hline Smoking & Satterthwaite et al, $1999^{17}$ & Blisters & Smoking & $\mathrm{OR}=0.39(0.17 \text { to } 0.88)^{*}$ \\
\hline $\begin{array}{l}\text { Participation in other } \\
\text { sports }\end{array}$ & Satterthwaite et al, $1999^{17}$ & $\begin{array}{l}\text { Stiffness and/or pain in front thigh } \\
\text { Stiffness and/or pain in hamstring }\end{array}$ & $\begin{array}{l}\text { Cycling } \\
\text { Aerobics }\end{array}$ & $\begin{array}{l}\mathrm{OR}=1.53(1.13 \text { to } 2.06)^{*} \\
\mathrm{OR}=1.74(1.05 \text { to } 2.89)^{*}\end{array}$ \\
\hline
\end{tabular}

*Represents adjusted OR or RR.

$\mathrm{Cl}$, confidence interval; $\mathrm{m}$, months; $\mathrm{OR}$, odds ratio.

association in both sexes was the same. This probably reflects a reduced statistical power in the female subgroup.

Fortunately, 12 studies reported the sites where the lower extremity running injuries occurred. Specific diagnoses, however, were discussed in only three studies and not even for all injured runners. ${ }^{10}{ }^{11}{ }^{20}$ Also the impact of these running injuries was rarely reported. Very little information was provided on the duration and severity of these injuries, and there was a lack of information about health care visits (for example, to general practitioner, physiotherapist, orthopaedic specialist) or the treatment used (drugs, rest, operation, other).

\section{Implications}

The presence of associations between determinants and running injuries suggests that advice and education may still be necessary. An unmodifiable risk factor is a history of previous injuries. Runners with this risk factor should pay extra attention to signs of injuries, avoid other determinants of injuries, and take time to recover fully from their injuries. The training distance per week is a modifiable risk factor and therefore runners should preferably not exceed $64 \mathrm{~km} /$ week.

Further investigation is necessary, because the incidence of running injuries in long distance runners is not clear and knowledge of the specific determinants of these injuries is still unsatisfactory. Future studies should clearly define the type of runners included (sprinters, middle distance, or long distance runners) and also specifically report information about training characteristics and race participation, so that the results can be applied on the correct group of runners. Also investigators should try to use a universal definition of running injury, so that results can easily be compared.

\section{What is already known on this topic?}

- Besides its positive heath effects, running may also cause injuries, especially to the lower extremities. Various studies have reported on the prevalence and incidence of running injuries occurring in long distance runners during training or races. Risk factors contributing to the occurrence of these injuries have also been reported.

\section{What this study adds}

- The incidence of lower extremity running injuries in published reports ranges from $20 \%$ to $79 \%$.

- The predominant site of these injuries is the knee.

- There is strong evidence that a long training distance per week in male runners and a history of previous injuries are risk factors for running injuries.
Likewise the length of observation period needs to be equal in different studies and the incidence numbers need to be expressed in comparable units.

Finally, to obtain information on the clinical consequences of running injuries, details on the duration and severity of these injuries, as well as information on the use of professional medical advice and the chosen treatment, is required.

\section{CONCLUSIONS}

The reported incidence of running injuries to the lower extremities in long distance runners varied from $19.4 \%$ to $92.4 \%$. The most common site of lower extremity running injuries was the knee. There is strong evidence that a greater training distance per week in male runners and a history of previous injuries are risk factors for lower extremity running injuries. We recommend further well designed studies on risk factors for running injuries for male and female runners.

\section{Authors' affiliations}

R N van Gent, D Siem, M van Middelkoop, A G van Os, S M A BiermaZeinstra, B W Koes, Erasmus MC Rotterdam, Netherlands

\section{REFERENCES}

1 De Loës M, Goldie I. Incidence rate of injuries during sport activity and physical exercise in a rural Swedish municipality: incidence rates in 17 sports. Int J Sports Med 1988:9:461-7.

2 Estok PJ, Rudy EB. Marathon running: comparison of physical and psychosocial risks for men and women. Res Nurs Health 1987;10:79-85.

3 Koplan JP, Rothenberg RB, Jones EL. The natural history of exercise: a 10-yr follow-up of a cohort of runners. Med Sci Sports Exerc 1995;27:1 180-4.

4 Neely FG. Intrinsic risk factors for exercise-related lower limb injuries. Sports Med 1998;26:253-63.

5 Johnston CA, Taunton JE, Lloyd-Smith DR, et al. Preventing running injuries. Practical approach for family doctors. Can Fam Physician 2006:49:1101-9.

6 Powell KE, Kohl HW, Caspersen CJ, et al. An epidemiological perspective on the causes of running injuries. Phys Sportsmed 1986;14:100-14

7 Landis JR, Koch GG. An application of hierarchical kappa-type statistics in the assessment of majority agreement among multiple observers. Biometrics 1977;33:363-74

8 Van Tulder MW, Furlan A, Bombardier C, et al. Updated method guidelines for systematic reviews in the cochrane collaboration back review group. Spine 2003;15:1290-9.

9 Bennell KL, Malcolm SA, Thomas SA, et al. The incidence and distribution of stress fractures in competitive track and field athletes. A twelve-month prospective study. Am J Sports Med 1996;24:211-17.

10 Bovens AMP, Janssen GME, Vermeer HGW, et al. Occurrence of running injuries in adults following a supervised training program. Int J Sports Med 1989;10:186-90.

11 Kretsch A, Grogan R, Duras P, et al. 1980 Melbourne marathon study. Med J Aust 1984;141:809-14.

12 Lun V, Meeuwisse WH, Stergiou P, et al. Relation between running injury and static lower limb alignment in recreational runners. Br J Sports Med 2004;38:576-80.

13 Lysholm J, Wiklander J. Injuries in runners. Am J Sports Med 1987;15:168-71.

14 Macera CA, Pate RR, Powell KE, et al. Predicting lower-extremity injuries among habitual runners. Arch Intern Med 1989;149:2565-8.

15 Nicholl JP, Williams BT. Popular marathons: forecasting casualties. BMJ (Clin Res Ed) 1982;20:1464-5.

16 Satterthwaite $\mathbf{P}$, Larmer $\mathrm{P}$, Gardiner J, et al. Incidence of injuries and other health problems in the Auckland Citibank marathon, 1993. Br J Sports Med 1996;30:324-6.

17 Satterthwaite $\mathbf{P}$, Norton R, Larmer $\mathrm{P}$, et al. Risk factors for injuries and other health problems sustained in a marathon. Br J Sports Med 1999;33:22-6. 
18 Steinacker Th, Steuer M, Höltke V. Orthopädische Probleme bei älteren Marathon läufern. [Orthopedic problems in older marathon runners.] Sportverletz Sportschaden 2001;15:12-15.

19 Taunton JE, Ryan MB, Clement DB, et al. A prospective study of running injuries: the Vancouver Sun Run "In Training" clinics. Br J Sports Med 2003;37:239-44.

20 Walter SD, Hart LE, Mclntosh JM, et al. The Ontario cohort study of runningrelated injuries. Arch Intern Med 1989;149:2561-4.

21 Wen DY, Puffer JC, Schmalzried TP. Injuries in runners: a prospective study of alignment. Clin J Sport Med 1998;8:187-94.

22 Jakobsen BW, Krøner K, Schmidt SA, et al. Løbeskader ved motionsmarathon. Registrering af skadehyppighed og skadetyper ved Århus Marathon 1986 [Running injuries sustained in a marathon race. Registration of the occurrence and types of injuries in the 1986 Arhus Marathon.] Ugeskr Laeger 1989;28:2189-21.

23 Macera CA, Pate RR, Woods J, et al. Postrace morbidity among runners. Am J Prev Med 1991;7:194-8.

24 Maughan RJ, Miller JDB. Incidence of training-related injuries among marathon runners. Br J Sports Med 1983;17:162-5

25 Nicholl JP, Williams BT. Medical problems before and after a popular marathon. BMJ (Clin Res Ed) 1982;20:1465-6.

26 Hoeberigs $\mathrm{JH}$. Factors related to the incidence of running injuries. A review. Sports Med 1992;13:408-22.

27 Macera CA. Lower extremity injuries in runners. Advances in prediction. Sports Med 1992;13:50-7.

28 Van Mechelen W. Running injuries. A review of the epidemiological literature. Sports Med 1992;14:320-35.

\section{APPENDIX}

\section{SPECIFICATION OF THE SEARCH STRATEGY USED IN THE PUBMED-MEDLINE DATABASE}

(runn*) AND (injur* OR syndrome* OR tend* OR fract* OR pain* OR fasciitis OR bursitis OR splint ${ }^{*}$ OR tear* OR sprain* OR strain $^{*}$ OR entrapment ${ }^{*}$ OR ostei or $^{*}$ OR osteop* ${ }^{*}$ OR osteom* OR osteoc* $^{*}$ OR osteoa* OR rupture* OR arthro* OR arthri* OR lipoma OR sciatica OR lumbago OR laceration* OR split* OR tenosynovitis OR blister* OR cramp* OR corn OR callus* OR edema* OR sesamoiditis OR ganglion* OR rhabdomyolisis OR hernia* OR muscle soreness OR delayed onset muscle soreness OR hemorrh* OR ischi* OR neurom* OR abrasion OR wart* OR mold $^{*}$ OR dislocation* OR damage OR trauma OR displacement OR periostitis) AND (patell ${ }^{*}$ OR knee ${ }^{*}$ OR tibial* ${ }^{*}$ fibular* OR spinal OR lumbar OR plantar OR calcaneal OR achilles* OR hamstring* OR ligament ${ }^{*}$ OR ankle* OR foot* OR infrapatellar OR hip OR back OR adductor* OR tigh* OR pubi* OR menisc* OR toe* OR lower extremity OR shin OR calve* OR neck OR shoulder OR groin OR ischia* OR sacral OR metatars* OR tars*) NOT ("addresses"[Publication Type] OR "bibliography" [Publication Type] OR "biography" [Publication Type] OR "case reports"[Publication Type] OR "clinical conference" [Publication Type] OR "comment"[Publication Type] OR "congresses"[Publication Type] OR "dictionary"[Publication Type] OR "directory"[Publication Type] OR "editorial"[Publication Type] OR
"festschrift"[Publication Type] OR "government publications"[Publication Type] OR "interview" [Publication Type] OR "lectures"[Publication Type] OR "legal cases"[Publication Type] OR "legislation"[Publication Type] OR "letter" [Publication Type] OR "news"[Publication Type] OR "newspaper article"[Publication Type] OR "retracted publication"[Publication Type] OR "retraction of publication" [Publication Type] OR "review"[Publication Type] OR "review literature" [Publication Type] OR "review of reported cases"[Publication Type] OR "review, academic"[Publication Type] OR "review, multicase" [Publication Type] OR "review, tutorial"[Publication Type] OR "scientific integrity review" ${ }^{\prime}$ Publication Type] OR "technical report" [Publication Type] OR "twin study"[Publication Type] OR "validation studies"[Publication Type]). Limits: Human.

\section{COMMENTARY}

This is a high quality review which is long overdue. The authors have included an excellent evaluation of the quality of papers selected for review process and very good criteria of selected variables. It is surprising that there is no inclusion of the strength of either core or hip abduction such as iliotibial band (ITB) injuries, knee injuries or possibly achilles injuries. The study allowed evaluation of location but not specific diagnosis. There is a good discussion of age and gender but not much on the role of downhill running, which is often attributed to knee injury (ITB, patellofemoral pain syndrome (PFPS) and patellar tendinosis). There is also a good discussion of previous injury, which has been highlighted recently, but not the degree of rehabilitation from previous injury. Recent biomechanical analysis points to a synchronous coupling of the lower extremity, related to the shoe and orthotic-that is, a loss of variability and capability to adapt to the surface as a factor in PFPS. See Ryan, MacLean and Taunton's latest review in Int Sports Med J.

Jack E Taunton University of British Columbia, Vancouver, BC, Canada jtaunton@interchange.ubc.ca

\section{REFERENCE}

1 Ryan M, MacLean C, Taunton J. A review of anthropometric, biomechanical, neuromuscular and training factors associated with injury in runners. Int Sport Med J 2006:7(2). http://www.ismi.com/default.asp?pagelD=562698171 \& article $=548095859$ (accessed 3 July 2007)

BNF for Children 2006, second annual edition

In a single resource:

- guidance on drug management of common childhood conditions

- hands-on information on prescribing, monitoring and administering medicines to children

- comprehensive guidance covering neonates to adolescents

For more information please go to bnfc.org 